\title{
Agenda para a pesquisa sobre o cuidado centrado no paciente no Brasil
}

\author{
Agenda for patient-centered care research in Brazil
}

Juliana Loureiro da Silva de Queiroz Rodrigues (http://orcid.org/0000-0002-2005-0377) ${ }^{1}$

Margareth Crisóstomo Portela (http://orcid.org/0000-0002-9858-9276) ${ }^{1}$

Ana Maria Malik (https://orcid.org/0000-0002-0813-8886) ${ }^{2}$

${ }^{1}$ Escola Nacional de Saúde Pública Sérgio Arouca,

Fundação Oswaldo Cruz. R. Leopoldo Bulhões 1480, Manguinhos. 21041-210 Rio de Janeiro RJ Brasil. juebe28@gmail.com ${ }^{2}$ Escola de Administração de Empresas de São Paulo, Fundação Getúlio Vargas. Bela Vista SP Brasil.

\begin{abstract}
Patient-centered care is an incipient movement and its practice still faces obstacles in the Brazilian health system, where it is not extensively identified as healthcare quality realm. Thus, this paper aims to establish a patient/person-centered care research agenda to support its implementation in the country's healthcare services. A panel was held with nine experts to grasp different views on the subject. The face-to-face discussion was supported by a document systematizing an initial agenda proposal and a brief presentation of the patient-centered care concept and theoretical elements that underpin its practice. Panel participants defined a set of items to be explored in studies to identify implementation and to strengthen and to measure strategies for patient-centered care in the Brazilian context.
\end{abstract}

Key words Person-centered care, Patient-centered care, Quality of care.
Resumo Ocuidado centrado no paciente se constitui em um movimento incipiente e sua prática ainda encontra obstáculos no sistema de saúde brasileiro, onde é pouco identificado como uma dimensão da qualidade dos cuidados de saúde. Baseado nisso, este artigo se propõe a estabelecer uma agenda de pesquisa sobre o cuidado centrado no paciente/pessoa, com vistas a subsidiar a sua implementação em serviços de saúde do país. Foi realizado um painel com nove especialistas, a fim de apreender diferentes olhares sobre o tema. A discussão presencial foi subsidiada por um documento sistematizando uma proposta inicial de agenda e uma breve apresentação sobre o conceito de cuidado centrado no paciente e elementos teóricos que conformam sua prática. Os participantes do painel definiram um conjunto de itens a serem explorados em estudos no sentido da identificação de estratégias de implementação, fortalecimento $e$ medição do cuidado centrado no paciente no contexto brasileiro.

Palavras-chave Cuidado centrado na pessoa, Assistência centrada no paciente, Qualidade do cuidado. 


\section{Introdução}

Donabedian ${ }^{1}$ já enfatizava as relações interpessoais como um componente fundamental no cuidado de saúde, o que sugere que a ideia de centralidade do cuidado de saúde no sujeito não é nova. Até hoje, não corresponde a um conceito preciso ${ }^{2}$ mas ganhou força neste milênio com a inclusão do "cuidado centrado no paciente" como um dos objetivos de um plano de melhoria da qualidade do cuidado de saúde nos Estados Unidos, conforme estabelecido no relatório Crossing the quality chasm: A new health system for the $21^{\text {st }}$ century, do Institute of Medicine (IOM). No documento, o cuidado centrado no paciente é definido como "a prestação de cuidado de forma respeitosa, respondendo às necessidades, preferências e valores da pessoa assistida, com a garantia de que tais valores norteiem todas as decisões clínicas"3.

Atualmente, uma diversidade de termos traduzem a centralidade do cuidado de saúde no sujeito. Tais termos são intercambiáveis e sua utilização pode variar de acordo com o contexto em que ocorre a prestação dos serviços de saúde ${ }^{4}$.

Há evidências que a prática do cuidado centrado no paciente produza efeitos positivos sobre os resultados clínicos, estimulando a cooperação e viabilizando o apoio e a consolidação dos seus direitos $^{5}$. Trata-se de um modelo de atenção que se propõe a romper paradigmas remanescentes do modelo biomédico e superar a fragmentação do cuidado ${ }^{6}$.

Porém, a implementação desta prática de cuidado representa um grande desafio para os serviços de saúde ${ }^{5-6}$. Tais desafios são atribuídos ao paternalismo, crenças e culturas da população; profissionais resistentes a mudanças por acreditarem já praticar o cuidado centrado no paciente; poucos estudos empíricos direcionadores; ausência de lideranças; e a infraestrutura do ambiente $^{5-7}$.

Os princípios que orientam a prática do cuidado centrado no paciente são: dignidade, compaixão e respeito; coordenação e integração do cuidado; cuidado personalizado; apoio ao autocuidado; informação, comunicação e educação; conforto físico; apoio emocional, alívio do medo e ansiedade; envolvimento de familiares e amigos; transição e continuidade; e, incorporado mais recentemente, acesso ao cuidado ${ }^{8}$.

Considerando a importância do tema e as peculiaridades do contexto brasileiro, é oportuna a proposição de uma agenda de elementos a serem priorizados na área de pesquisa, com vistas à implementação efetiva do cuidado centrado no pa- ciente nos serviços de saúde. Nesse sentido, este artigo tem o objetivo de apresentar uma agenda que subsidie o desenvolvimento de estudos capazes de apontarem estratégias para a implementação do "cuidado centrado no paciente" em serviços de saúde no Brasil.

\section{Métodos}

Foi realizado um painel de especialistas, na expectativa de apreender diferentes olhares, teóricos e práticos, sobre "cuidado centrado no paciente". Para o painel foram convidados 11 profissionais, contemplando afinidade com o tema e atuação na prestação de serviços de saúde em estabelecimentos no setor privado ou público, seja em atividades de planejamento e coordenação de ações em instituições gestoras do SUS, seja em atividades acadêmicas. A representação de categorias não foi uma preocupação na escolha dos participantes. Julgou-se ainda relevante a participação de um paciente engajado na luta pela defesa dos pacientes, buscando-se esse indivíduo em uma associação de pacientes (Quadro 1).

Após consentimento dos participantes, o debate foi gravado a fim de resguardar todas as contribuições técnicas, vinculando-as aos temas de discussão propostos, e subsidiar a análise dos resultados do painel (Quadro 2).

Em contato com o Comitê de Ética em Pesquisa (CEP) da instituição onde se promoveu o painel, argumentou-se que os membros de um painel de especialistas são convidados para prover opiniões técnicas, baseadas em seu conhecimento e experiência. Assim, eles não estão em condição de vulnerabilidade, justificando a não necessidade de submissão ao referido Comitê. Após consulta do CEP à Comissão Nacional de Ética em Pesquisa, o argumento foi aceito.

\section{Resultados}

O encontro dos especialistas foi realizado no dia 21 de maio de 2015, com duração de seis horas. Apesar de todos os convidados terem manifestado interesse, apenas nove especialistas participaram do painel. Como ponto de partida, foi realizada breve apresentação do conceito de cuidado centrado no paciente, elementos teóricos e a relevância de discussão do tema nos contextos brasileiro e internacional. $\mathrm{O}$ painel chegou ao consenso de que o contexto teórico da discussão sobre cuidado centrado no paciente guarda estreita relação com outras dimensões da qualida- 
Quadro 1. Composição do Painel de Especialistas.

\begin{tabular}{|l|c|}
\hline \multicolumn{1}{|c|}{ Perfil } & Participante \\
\hline Representante de associação de pacientes & X \\
\hline Advogada. Professora especialista em Bioética e Direitos Humanos. & X \\
\hline Médica. Professora e Pesquisadora no campo da Gestão em Saúde & X \\
\hline Médica. Gestora no nível municipal. & X \\
\hline $\begin{array}{l}\text { Enfermeira. Doutora em Saúde Pública. Especialista em Vigilância em Saúde e Segurança do } \\
\text { Paciente. }\end{array}$ & X \\
\hline $\begin{array}{l}\text { Médica. Doutora em Saúde Pública. Professora e Pesquisadora no campo da Qualidade do Cuidado } \\
\text { de Saúde }\end{array}$ & X \\
\hline Médica. Intensivista e Assessora de Qualidade em um hospital especializado de grande porte & X \\
\hline $\begin{array}{l}\text { Médica. Doutora em Saúde Pública. Atua como especialista em Endocrinologia em consultório } \\
\text { privado. }\end{array}$ & X \\
\hline $\begin{array}{l}\text { Terapeuta ocupacional. Mestre em Saúde Pública com dissertação dedicada ao tema do cuidado } \\
\text { centrado no paciente/pessoa. }\end{array}$ & X \\
\hline $\begin{array}{l}\text { Médico. Doutor em Saúde Coletiva. Professor e Pesquisador atuante no campo da Bioética } \\
\text { Médica. Doutora em Saúde Pública. Geriatra atuante na Atenção Primária, no setor público e no } \\
\text { setor privado. }\end{array}$ & \\
\hline
\end{tabular}

Quadro 2. Pontos abordados no documento base submetido ao painel de especialistas.

\begin{tabular}{|c|c|c|}
\hline \multicolumn{3}{|c|}{ Definição de uma Agenda de Pesquisa e Abordagem do Cuidado Centrado no Paciente no Brasil } \\
\hline Objetivo & \multicolumn{2}{|c|}{$\begin{array}{l}\text { Estabelecer uma agenda para a pesquisa e abordagem do cuidado centrado no paciente } \\
\text { no âmbito dos serviços de saúde, partindo da apreciação e indicação (ou não) de uma } \\
\text { designação terminológica preferencial. }\end{array}$} \\
\hline Proposta estratégia & \multicolumn{2}{|c|}{$\begin{array}{l}\text { Discussão breve sobre as designações "cuidado centrado no paciente" e "cuidado centrado } \\
\text { na pessoa", com vistas à indicação de um termo de escolha a ser preconizado no contexto } \\
\text { de saúde brasileiro, seguida por um debate sobre pontos a comporem a agenda. }\end{array}$} \\
\hline Resultados esperados & \multicolumn{2}{|c|}{$\begin{array}{l}\text { Estabelecimento da agenda e a elaboração de um artigo contendo a sistematização do } \\
\text { trabalho realizado, tendo como coautores todos os participantes do painel. }\end{array}$} \\
\hline \multicolumn{3}{|c|}{ Agenda submetida ao painel } \\
\hline Item & Justificativa & Principais questões \\
\hline $\begin{array}{l}\text { O conceito de } \\
\text { "cuidado centrado no } \\
\text { paciente }\end{array}$ & $\begin{array}{l}\text { Os conceitos propiciam a } \\
\text { operacionalização das intervenções e } \\
\text { práticas de saúde. }\end{array}$ & $\begin{array}{l}\text { Quais são os atributos do cuidado centrado } \\
\text { no paciente a serem prioritariamente } \\
\text { operacionalizados na realidade da atenção à } \\
\text { saúde no Brasil, considerando a diversidade } \\
\text { territorial? }\end{array}$ \\
\hline $\begin{array}{l}\text { Aspectos contextuais } \\
\text { relevantes para a } \\
\text { implementação do } \\
\text { cuidado centrado no } \\
\text { paciente. }\end{array}$ & $\begin{array}{l}\text { Reconhecimento de que fatores } \\
\text { contextuais influenciam o sucesso (ou } \\
\text { não) das intervenções, no sentido de } \\
\text { melhoria da qualidade do cuidado de } \\
\text { saúde e interação dinâmica com tais } \\
\text { ações. }\end{array}$ & $\begin{array}{l}\text { Quais são os aspectos contextuais que facilitam } \\
\text { ou dificultam uma cultura no sentido da } \\
\text { provisão do cuidado de saúde centrado no } \\
\text { paciente? A provisão do cuidado centrado } \\
\text { no paciente varia conforme os efeitos desses } \\
\text { aspectos contextuais? }\end{array}$ \\
\hline $\begin{array}{l}\text { As estratégias políticas } \\
\text { para implementação } \\
\text { do cuidado centrado } \\
\text { no paciente como } \\
\text { dimensão da qualidade } \\
\text { do cuidado de saúde } \\
\text { no Brasil. } \\
\end{array}$ & $\begin{array}{l}\text { Não há no Brasil, uma política } \\
\text { de saúde que reconheça e apoie } \\
\text { inteiramente o cuidado centrado } \\
\text { na pessoa como uma dimensão da } \\
\text { qualidade dos serviços de saúde. }\end{array}$ & $\begin{array}{l}\text { Cabe o estabelecimento de uma política neste } \\
\text { sentido? Quais estratégias seriam cabíveis nas } \\
\text { três esferas de governo no âmbito institucional, } \\
\text { da atenção à saúde, do financiamento e da gestão } \\
\text { do trabalho, no sentido de desenvolvimento das } \\
\text { habilidades dos trabalhadores? }\end{array}$ \\
\hline $\begin{array}{l}\text { A comunicação entre } \\
\text { profissionais de saúde } \\
\text { e pacientes }\end{array}$ & $\begin{array}{l}\text { A comunicação é o elemento chave } \\
\text { para todo e qualquer tipo de relação. A } \\
\text { forma como é desenvolvida é capaz de } \\
\text { determinar o sucesso ou fracasso da } \\
\text { relação entre profissionais de saúde e } \\
\text { profissionais e pacientes. }\end{array}$ & $\begin{array}{l}\text { Quais os desafios presentes para o } \\
\text { desenvolvimento da comunicação? } \\
\text { Como melhorar a comunicação entre } \\
\text { profissionais de saúde e entre profissionais e } \\
\text { pacientes no sentido de promover o cuidado } \\
\text { centrado no paciente? }\end{array}$ \\
\hline
\end{tabular}


Quadro 2. Pontos abordados no documento base submetido ao painel de especialistas.

\begin{tabular}{|c|c|c|}
\hline \multicolumn{3}{|c|}{ Agenda submetida ao painel } \\
\hline Item & Justificativa & Principais questões \\
\hline $\begin{array}{l}\text { O compartilhamento } \\
\text { de decisões como } \\
\text { elemento do cuidado } \\
\text { centrado no paciente. }\end{array}$ & $\begin{array}{l}\text { São grandes os desafios para o } \\
\text { compartilhamento de decisões nos } \\
\text { serviços de saúde: a comunicação } \\
\text { fragilizada, uma prática centrada } \\
\text { exclusivamente no profissional, } \\
\text { aspectos culturais e organizacionais, } \\
\text { a insuficiência de recursos humanos } \\
\text { e a sobrecarga de serviços, podem } \\
\text { contribuir para um cuidado com } \\
\text { baixa participação dos pacientes } \\
\text { e familiares, mais centrada nos } \\
\text { interesses institucionais e dos } \\
\text { profissionais de saúde. }\end{array}$ & $\begin{array}{l}\text { Como vencer a resistência dos profissionais } \\
\text { de saúde? Como lidar com questões como a } \\
\text { desproporcionalidade de recursos humanos à } \\
\text { demanda? } \\
\text { Que limites são importantes, do ponto de } \\
\text { vista do paciente, para o compartilhamento de } \\
\text { decisões? }\end{array}$ \\
\hline $\begin{array}{l}\text { Aspectos contextuais } \\
\text { interferem na } \\
\text { continuidade do } \\
\text { cuidado e adesão ao } \\
\text { plano terapêutico }\end{array}$ & $\begin{array}{l}\text { As práticas de saúde interagem } \\
\text { dinamicamente com aspectos } \\
\text { internos, inerentes à organização das } \\
\text { ações e serviços de saúde, e externos, } \\
\text { caracterizados pela influência de } \\
\text { outros setores da sociedade, fatore } \\
\text { individuais, coletivos e culturais de } \\
\text { uma comunidade. }\end{array}$ & $\begin{array}{l}\text { Como os aspectos culturais e as diferentes } \\
\text { concepções de saúde interferem na continuidade } \\
\text { do cuidado de saúde? } \\
\text { Até que ponto, a maneira como o sistema de } \\
\text { saúde está organizado propicia ou dificulta a } \\
\text { continuidade do cuidado? }\end{array}$ \\
\hline $\begin{array}{l}\text { A relação entre } \\
\text { integralidade e cuidado } \\
\text { centrado no paciente. }\end{array}$ & $\begin{array}{l}\text { A integralidade é um dos princípios do } \\
\text { SUS que deve nortear todas as práticas } \\
\text { de saúde }\end{array}$ & $\begin{array}{l}\text { A prática do cuidado centrado no paciente é } \\
\text { capaz de promover a integralidade do cuidado? }\end{array}$ \\
\hline $\begin{array}{l}\text { A incorporação de } \\
\text { mudanças curriculares } \\
\text { e nos processos de } \\
\text { formação no sentido } \\
\text { de promover uma nova } \\
\text { orientação teórica e } \\
\text { práticas de saúde. }\end{array}$ & \begin{tabular}{|l|} 
A Educação e treinamento do \\
profissional de saúde ainda está, \\
predominantemente, sob uma \\
perspectiva biomédica (DNV/GL, \\
2013, p.126). As mudanças sociais \\
decorrentes do processo de transição \\
demográfica e epidemiológica, \\
modificam as demandas e necessidades \\
da população.
\end{tabular} & $\begin{array}{l}\text { Considerando o envelhecimento populacional } \\
\text { e o predomínio das condições crônicas de } \\
\text { saúde, que tipo de disciplinas poderiam ser } \\
\text { incorporadas nas bases curriculares? Que novas } \\
\text { demandas e responsabilidades são impostas à } \\
\text { academia? }\end{array}$ \\
\hline $\begin{array}{l}\text { O cuidado centrado } \\
\text { no paciente para } \\
\text { a produção de um } \\
\text { cuidado seguro. }\end{array}$ & $\begin{array}{l}\text { Alta incidência de eventos adversos no } \\
\text { Brasil. O envolvimento dos pacientes } \\
\text { e seus familiares no cuidado da sua } \\
\text { saúde contribuem para um tratamento } \\
\text { mais seguro. Preocupação dos sistemas } \\
\text { de saúde com a questão da qualidade } \\
\text { do cuidado e da segurança do paciente. }\end{array}$ & $\begin{array}{l}\text { Em que grau a legitimação do paciente e } \\
\text { acompanhantes no processo de cuidado } \\
\text { contribui para um cuidado seguro? } \\
\text { Como o paciente e acompanhantes podem ser } \\
\text { envolvidos no processo de cuidado de saúde de } \\
\text { modo a torná-lo mais seguro? }\end{array}$ \\
\hline $\begin{array}{l}\text { Criação de } \\
\text { instrumentos de } \\
\text { mensuração específicos } \\
\text { voltados para estudos } \\
\text { dos elementos que } \\
\text { conformam o cuidado } \\
\text { centrado no paciente. } \\
\end{array}$ & $\begin{array}{l}\text { Instrumentos para mensuração de } \\
\text { componentes do cuidado centrado } \\
\text { no paciente são utilizados, com maior } \\
\text { ênfase nos países desenvolvidos. No } \\
\text { Brasil não é reconhecido a validação de } \\
\text { um instrumento capaz de mensurar o } \\
\text { cuidado centrado no paciente. }\end{array}$ & $\begin{array}{l}\text { Até que ponto a criação e validação de um } \\
\text { instrumento de mensuração do cuidado } \\
\text { centrado no paciente pode contribuir para a } \\
\text { melhoria da qualidade da atenção? }\end{array}$ \\
\hline $\begin{array}{l}\text { Desenvolvimento de } \\
\text { trabalhos empíricos no } \\
\text { Brasil sobre o cuidado } \\
\text { centrado na pessoa. }\end{array}$ & $\begin{array}{l}\text { O desenvolvimento de trabalhos } \\
\text { empíricos no Brasil que reconheça o } \\
\text { cuidado centrado no paciente, como } \\
\text { dimensão da qualidade dos serviços de } \\
\text { saúde ainda é insuficiente. }\end{array}$ & $\begin{array}{l}\text { As percepções sobre o cuidado centrado no } \\
\text { paciente existentes no contexto de saúde } \\
\text { brasileiro se distinguem daquelas observadas nos } \\
\text { países desenvolvidos? } \\
\text { Considerando as diversas perspectivas do } \\
\text { cuidado centrado no paciente, como incentivar } \\
\text { o desenvolvimento de trabalhos empíricos no } \\
\text { Brasil voltados para esta temática? Há questões } \\
\text { especialmente relevantes? }\end{array}$ \\
\hline
\end{tabular}


Quadro 3. Resultado final da discussão consolidado: Agenda proposta pelo painel.

\begin{tabular}{|c|c|c|c|}
\hline \multicolumn{4}{|c|}{ Recomendações para o cuidado centrado no paciente } \\
\hline Item & Justificativa & Principais questões & Principais pontos levantados \\
\hline $\begin{array}{l}\text { O conceito } \\
\text { de "cuidado } \\
\text { centrado na } \\
\text { pessoa/paciente }\end{array}$ & $\begin{array}{l}\text { Os conceitos } \\
\text { propiciam a } \\
\text { comunicação entre } \\
\text { os indivíduos. }\end{array}$ & $\begin{array}{l}\text { O que define o conceito } \\
\text { de cuidado centrado no } \\
\text { paciente }(\mathrm{CCP}) \text { para a } \\
\text { realidade brasileira? }\end{array}$ & $\begin{array}{l}\text { Optou-se pela utilização do termo } \\
\text { "cuidado centrado na pessoa. } \\
\text { Destacou-se, entretanto, que a escolha } \\
\text { do termo pode ser condicionada ao } \\
\text { nível de complexidade em que se dá a } \\
\text { prestação do cuidado e, neste sentido, } \\
\text { enfatizou-se a necessidade de cautela } \\
\text { a fim de se evitar descaracterizações, } \\
\text { obscuridades e perda do foco central do } \\
\text { cuidado de saúde. Não se chegou a uma } \\
\text { definição precisa do cuidado centrado } \\
\text { na pessoa, ficando a proposta de se } \\
\text { constituir uma agenda específica para } \\
\text { esta discussão. }\end{array}$ \\
\hline \begin{tabular}{|l} 
Aspectos \\
contextuais \\
relevantes para a \\
implementação \\
do cuidado \\
centrado na \\
pessoa/paciente.
\end{tabular} & $\begin{array}{l}\text { Reconhecimento } \\
\text { de que fatores } \\
\text { contextuais, em } \\
\text { diferentes níveis, } \\
\text { influenciam o sucesso } \\
\text { (ou não) de ações. }\end{array}$ & $\begin{array}{l}\text { Quais são os aspectos } \\
\text { contextuais que facilitam } \\
\text { ou dificultam uma } \\
\text { cultura de provisão } \\
\text { do cuidado de saúde } \\
\text { centrado no paciente? }\end{array}$ & $\begin{array}{l}\text { O reconhecimento de aspectos } \\
\text { contextuais é essencial quando se quer } \\
\text { promover mudanças. As variações de } \\
\text { contexto influenciam as práticas de } \\
\text { saúde, afetando sua efetividade. } \\
\text { Os aspectos de contexto aracterizam-se } \\
\text { por práticas organizacionais, tais como } \\
\text { o trabalho em equipe, bem como tudo } \\
\text { que está no entorno das práticas que } \\
\text { pode constituir entrave ou facilitar a } \\
\text { implementação do cuidado centrado na } \\
\text { pessoa/paciente. }\end{array}$ \\
\hline $\begin{array}{l}\text { As estratégias } \\
\text { políticas para } \\
\text { implementação } \\
\text { do cuidado } \\
\text { centrado na } \\
\text { pessoa. }\end{array}$ & $\begin{array}{l}\text { Ainda que } \\
\text { existam políticas } \\
\text { que considerem } \\
\text { elementos do cuidado } \\
\text { centrado na pessoa } \\
\text { em sua composição e } \\
\text { na definição de suas } \\
\text { estratégias, ainda não } \\
\text { há uma política de } \\
\text { saúde voltada para o } \\
\text { cuidado centrado na } \\
\text { pessoa no país. }\end{array}$ & $\begin{array}{l}\text { Cabe o estabelecimento } \\
\text { de uma política neste } \\
\text { sentido? Quais estratégias } \\
\text { seriam cabíveis? Quais as } \\
\text { similaridades e diferenças } \\
\text { existentes entre a PNH } \\
\text { e o cuidado centrado na } \\
\text { pessoa? }\end{array}$ & $\begin{array}{l}\text { Não se nega a existência de interfaces } \\
\text { entre o cuidado centrado na pessoa e } \\
\text { a Política Nacional de Humanização } \\
\text { (PNH), mas se reconhece que não se } \\
\text { tratam da mesma coisa. Destacou-se a } \\
\text { contribuição do cuidado centrado na } \\
\text { pessoa para um cuidado seguro. Fica } \\
\text { proposto que se busque estabelecer uma } \\
\text { interlocução entre grupos que atuam na } \\
\text { área da qualidade do cuidado de saúde } \\
\text { e o grupo que participa da formulação } \\
\text { da PNH. }\end{array}$ \\
\hline $\begin{array}{l}\text { A comunicação } \\
\text { entre } \\
\text { profissionais } \\
\text { de saúde e } \\
\text { pacientes. }\end{array}$ & $\begin{array}{l}\text { Toda relação } \\
\text { construída entre } \\
\text { profissionais, } \\
\text { pacientes e familiares } \\
\text { é permeada pela } \\
\text { comunicação } \\
\text { e por aspectos } \\
\text { organizacionais } \\
\text { que interferem na } \\
\text { continuidade do } \\
\text { tratamento. }\end{array}$ & $\begin{array}{l}\text { Quais os desafios para } \\
\text { o desenvolvimento } \\
\text { de habilidades de } \\
\text { comunicação? Qual o } \\
\text { papel das tecnologias } \\
\text { na comunicação } \\
\text { desenvolvida nos serviços } \\
\text { de saúde? } \\
\text { Como promover a } \\
\text { melhoria da comunicação } \\
\text { entre profissionais } \\
\text { de saúde e entre } \\
\text { profissionais e pacientes } \\
\text { no sentido de promover } \\
\text { o cuidado centrado na } \\
\text { pessoa? }\end{array}$ & $\begin{array}{l}\text { Elementos organizacionais e a falta } \\
\text { de habilidades comunicacionais são } \\
\text { aspectos que podem interferir no } \\
\text { processo de comunicação. } \\
\text { Dentre os fatores organizacionais } \\
\text { destacados: tempo de consulta; o } \\
\text { ambiente da consulta médica; o papel das } \\
\text { tecnologias na organização do cuidado; } \\
\text { a redução dos gradientes de hierarquia } \\
\text { nas relações entre profissionais; o } \\
\text { compartilhamento de informações; a } \\
\text { criação de meios que possibilitem a } \\
\text { aquisição de informações precisas e } \\
\text { confiáveis; aumento da literacia em } \\
\text { saúde. } \\
\text { Uma comunicação efetiva contribui para } \\
\text { o compartilhamento de informações. }\end{array}$ \\
\hline
\end{tabular}


de do cuidado de saúde, incorrendo em questões pertinentes à própria complexidade do cuidado na atualidade.
O Quadro 3 sistematiza o resultado final do debate que se travou, sendo alguns elementos destacados a seguir.

Quadro 3. Resultado final da discussão consolidado: Agenda proposta pelo painel.

\begin{tabular}{|c|c|c|c|}
\hline \multicolumn{4}{|c|}{ Recomendações para o cuidado centrado no paciente } \\
\hline Item & Justificativa & Principais questões & Principais pontos levantados \\
\hline $\begin{array}{l}\text { O } \\
\text { compartil- } \\
\text { hamento de } \\
\text { informações e } \\
\text { decisões como } \\
\text { elemento do } \\
\text { cuidado centra- } \\
\text { do na pessoa }\end{array}$ & $\begin{array}{l}\text { Há grandes } \\
\text { desafios para que o } \\
\text { compartilhamento } \\
\text { de decisões seja uma } \\
\text { prática frequente nos } \\
\text { serviços de saúde. }\end{array}$ & $\begin{array}{l}\text { Que limites são } \\
\text { importantes, do ponto de } \\
\text { vista do paciente, para } \\
\text { o compartilhamento de } \\
\text { decisões? }\end{array}$ & $\begin{array}{l}\text { A comunicação é um elemento essencial } \\
\text { para o compartilhamento de decisões. } \\
\text { A privacidade foi citada como um } \\
\text { princípio que deve ser respeitado e } \\
\text { preservado. } \\
\text { A declaração de direitos do paciente foi } \\
\text { apontada como um documento que deve } \\
\text { estar disponibilizado nos serviços de } \\
\text { saúde. } \\
\text { A confiança influencia no } \\
\text { compartilhamento das decisões. } \\
\text { As notícias veiculadas pela mídia } \\
\text { alimenta a "cultura do medo" e interfere } \\
\text { na construção da confiança. }\end{array}$ \\
\hline $\begin{array}{l}\text { Aspectos } \\
\text { contextuais que } \\
\text { interferem na } \\
\text { continuidade } \\
\text { do cuidado e } \\
\text { adesão ao plano } \\
\text { terapêutico }\end{array}$ & & & $\begin{array}{l}\text { Fica a proposta de desmembramento } \\
\text { deste item: a "continuidade do cuidado" } \\
\text { foi referida como uma dimensão } \\
\text { do sistema de saúde; a "adesão" foi } \\
\text { relacionada a aspectos inerentes ao } \\
\text { sujeito do cuidado, mas que não } \\
\text { negligencia o aspectos organizacionais. }\end{array}$ \\
\hline $\begin{array}{l}\text { A relação do } \\
\text { princípio da } \\
\text { integralidade } \\
\text { com o modelo } \\
\text { de cuidado } \\
\text { centrado no } \\
\text { paciente. }\end{array}$ & & & $\begin{array}{l}\text { Recomendou-se a retirada deste item, } \\
\text { visto que, a integralidade consiste em } \\
\text { um conceito multidimensional que } \\
\text { não deve ser discutido isoladamente; } \\
\text { Considerou-se a necessidade de um } \\
\text { referencial para discutir integralidade. } \\
\text { A integralidade foi destacada como a } \\
\text { essência do cuidado centrado na pessoa. }\end{array}$ \\
\hline $\begin{array}{l}\text { A incorporação } \\
\text { de mudanças } \\
\text { nas bases } \\
\text { curriculares e } \\
\text { nos processos } \\
\text { de formação no } \\
\text { sentido de uma } \\
\text { nova orientação } \\
\text { teórica e das } \\
\text { práticas em } \\
\text { saúde. }\end{array}$ & $\begin{array}{l}\text { A educação e } \\
\text { treinamento do } \\
\text { profissional de } \\
\text { saúde ainda estão } \\
\text { predominantemente } \\
\text { dominados pela } \\
\text { perspectiva biomédica } \\
\text { (DNV/GL, 2013, } \\
\text { p.126), mas as } \\
\text { mudanças sociais } \\
\text { decorrentes do } \\
\text { processo de transição } \\
\text { demográfica e } \\
\text { epidemiológica, } \\
\text { modificam as } \\
\text { demandas e } \\
\text { necessidades da } \\
\text { população. }\end{array}$ & $\begin{array}{l}\text { Considerando o } \\
\text { envelhecimento } \\
\text { populacional e o } \\
\text { predomínio das } \\
\text { condições crônicas } \\
\text { de saúde, que tipo de } \\
\text { disciplinas poderiam } \\
\text { ser incorporadas nas } \\
\text { bases curriculares? } \\
\text { Que novas demandas } \\
\text { e responsabilidades são } \\
\text { impostas à academia? }\end{array}$ & $\begin{array}{l}\text { A influência do mercado na formação } \\
\text { dos profissionais de saúde; } \\
\text { O Estado como indutor de mudanças } \\
\text { no processo de cuidado; } \\
\text { Inclusão de disciplinas teórico-práticas } \\
\text { voltadas para o desenvolvimento da } \\
\text { empatia e compaixão; } \\
\text { A interdisciplinaridade e o trabalho em } \\
\text { equipe são elementos importantes a } \\
\text { serem incentivados durante o processo } \\
\text { de formação. }\end{array}$ \\
\hline
\end{tabular}


Quadro 3. Resultado final da discussão consolidado: Agenda proposta pelo painel.

\begin{tabular}{|c|c|c|c|}
\hline \multicolumn{4}{|c|}{ Recomendações para o cuidado centrado no paciente } \\
\hline Item & Justificativa & Principais questões & Principais pontos levantados \\
\hline $\begin{array}{l}\text { O cuidado } \\
\text { centrado na } \\
\text { pessoa para } \\
\text { produção de um } \\
\text { cuidado seguro }\end{array}$ & $\begin{array}{l}\text { Alta incidência de } \\
\text { eventos adversos no } \\
\text { Brasil. } \\
\text { Evidências que } \\
\text { o envolvimento } \\
\text { de pacientes e } \\
\text { seus familiares no } \\
\text { cuidado contribuem } \\
\text { para um cuidado mais } \\
\text { seguro. } \\
\text { Preocupação dos } \\
\text { sistemas de saúde } \\
\text { com a questão da } \\
\text { qualidade do cuidado } \\
\text { e da segurança do } \\
\text { paciente. }\end{array}$ & $\begin{array}{l}\text { Em que grau a } \\
\text { legitimação do paciente } \\
\text { e companhantes no } \\
\text { processo de cuidado } \\
\text { contribui para um } \\
\text { cuidado seguro? } \\
\text { Como o paciente e } \\
\text { acompanhantes podem } \\
\text { ser envolvidos no } \\
\text { processo de cuidado de } \\
\text { saúde de modo a torna- } \\
\text { lo mais seguro? }\end{array}$ & $\begin{array}{l}\text { A legitimação do paciente e } \\
\text { acompanhantes no processo de cuidado } \\
\text { contribui em alto grau para um cuidado } \\
\text { seguro; } \\
\text { O compartilhamento de informações é } \\
\text { essencial para um cuidado mais seguro. }\end{array}$ \\
\hline $\begin{array}{l}\text { Criação de } \\
\text { instrumentos } \\
\text { de mensuração } \\
\text { específicos } \\
\text { voltados para } \\
\text { estudo de } \\
\text { elementos } \\
\text { do cuidado } \\
\text { centrado na } \\
\text { pessoa. }\end{array}$ & $\begin{array}{l}\text { Instrumentos para } \\
\text { mensuração de } \\
\text { componentes do } \\
\text { cuidado centrado } \\
\text { na pessoa/paciente } \\
\text { são utilizados, com } \\
\text { maior ênfase nos } \\
\text { países desenvolvidos. } \\
\text { E uma área em que } \\
\text { o Brasil precisa } \\
\text { avançar, validando } \\
\text { instrumentos } \\
\text { existentes ou } \\
\text { propondo novos } \\
\text { instrumentos. }\end{array}$ & $\begin{array}{l}\text { Que dimensões e aspectos } \\
\text { devem ser considerados } \\
\text { na mensuração do } \\
\text { cuidado centrado na } \\
\text { pessoa. Em que medida a } \\
\text { proposição ou validação } \\
\text { deinstrumentos de } \\
\text { mensuração do cuidado } \\
\text { centrado na pessoa/ } \\
\text { paciente pode contribuir } \\
\text { para a melhoria da } \\
\text { qualidade da atenção? }\end{array}$ & $\begin{array}{l}\text { Destacou-se a possibilidade da } \\
\text { adaptação de instrumentos } \\
\text { internacionais utilizados para } \\
\text { mensuração de elementos do cuidado } \\
\text { centrado no paciente ou até mesmo a } \\
\text { livre criação condizente com a cultura } \\
\text { do cuidado de saúde no Brasil }\end{array}$ \\
\hline $\begin{array}{l}\text { Desenvolvimento } \\
\text { de trabalhos } \\
\text { empíricos no } \\
\text { Brasil sobre } \\
\text { o cuidado } \\
\text { centrado na } \\
\text { pessoa }\end{array}$ & $\begin{array}{l}\text { O desenvolvimento de } \\
\text { trabalhos empíricos } \\
\text { no Brasil sobre o } \\
\text { cuidado centrado } \\
\text { na pessoa/ paciente, } \\
\text { que reconheça-o } \\
\text { como dimensão da } \\
\text { qualidade dos serviços } \\
\text { de saúde ainda é } \\
\text { insuficiente. }\end{array}$ & $\begin{array}{l}\text { As percepções sobre o } \\
\text { cuidado centrado na } \\
\text { pessoa/paciente existentes } \\
\text { no contexto de saúde } \\
\text { brasileiro se distinguem } \\
\text { daquelas observadas nos } \\
\text { países desenvolvidos? } \\
\text { Considerando as } \\
\text { diversas perspectivas } \\
\text { do cuidado centrado } \\
\text { na pessoa/paciente, } \\
\text { como incentivar o } \\
\text { desenvolvimento de } \\
\text { trabalhos empíricos no } \\
\text { Brasil voltados para esta } \\
\text { temática? Há questões } \\
\text { especialmente relevantes? }\end{array}$ & $\begin{array}{l}\text { Destacou-se a insuficiência de } \\
\text { trabalhos empíricos no Brasil na área } \\
\text { da qualidade dos serviços de saúde } \\
\text { de uma maneira geral, sublinhando- } \\
\text { se, em particular, a necessidade de } \\
\text { subsídios governamentais e financeiros } \\
\text { de fomento ao desenvolvimento de } \\
\text { pesquisas sobre o cuidado centrado na } \\
\text { pessoa. Foi levantado que há poucos } \\
\text { trabalhos no Brasil sobre o cuidado } \\
\text { centrado na pessoa/paciente e os } \\
\text { que existem possuem denominações } \\
\text { genéricas e estudam isoladamente } \\
\text { elementos teóricos desta prática de } \\
\text { cuidado. }\end{array}$ \\
\hline
\end{tabular}

\section{$O$ conceito de cuidado centrado na pessoa/paciente}

Considerando a diversidade de termos que expressam a centralidade do cuidado de saúde no sujeito, foram apresentadas aos participantes duas opções consideradas mais adequadas nos serviços de saúde: cuidado centrado no paciente e cuidado centrado na pessoa. A pré-seleção dessas expressões foi calcada no fato do vocábulo 
"paciente" ainda ser bastante utilizado no contexto de prestação de cuidados de saúde, e "pessoa" ser mais abrangente e ter muitos defensores na literatura nacional e internacional.

Admitindo especificidades e sobreposição dos termos apresentados, o painel concluiu que o uso da expressão "cuidado centrado na pessoa" seria mais congruente à realidade do sistema de saúde brasileiro. Segundo as opiniões, o vocábulo "paciente" restringe a abordagem do sujeito e sugere certa vulnerabilidade daquele que recebe o cuidado de saúde, além de excluir o componente da promoção da saúde.

Porém, se atentou também para a necessidade de cautela em afirmar que a expressão "cuidado centrado na pessoa" é mais apropriada do que "cuidado centrado no paciente", no sentido de evitar descaracterizações e perda do foco central do cuidado.

\section{Aspectos contextuais relevantes para a implementação do cuidado centrado no paciente/pessoa}

Segundo o painel, as características organizacionais, determinadas pela forma como as ações e serviços de saúde estão organizados no âmbito do sistema, repercutem diretamente na operacionalização das práticas de saúde. Dessa forma, pode-se dizer que as políticas públicas, a organização do processo de trabalho, a disponibilidade de recursos, os valores organizacionais, a liderança e os valores individuais de cada pessoa, exercem influência no modo como uma instituição planeja e implementa suas atividades.

\section{Estratégias para implementação do cuidado centrado no paciente/pessoa}

Ainda que se admita a importância do cuidado centrado no paciente para a melhoria da qualidade dos serviços de saúde, ficou claro que não há no Brasil uma política que integre todos os elementos teóricos e princípios necessários para a conformação desta prática de cuidado. Segundo os participantes, há interfaces entre elementos do cuidado centrado no paciente e a Política Nacional de Humanização (PNH), porém esta última não trabalha o conceito em sua plenitude.

Assumindo que, no contexto brasileiro, a PNH emergiu como uma estratégia transversal de produção e reorganização das práticas coletivas de atenção e gestão, foi proposta a interlocução entre pesquisadores que se debruçam em estudos sobre qualidade do cuidado de saúde e profissionais que participaram da formulação e implantação dessa política a fim de comparar aspectos contemplados pela $\mathrm{PNH}$ com elementos do cuidado centrado no paciente. Tal comparação propiciará circunstâncias favoráveis à implementação da prática do cuidado centrado no paciente, a partir da identificação de elementos comuns ou divergentes entre ambos.

\section{A comunicação entre profissionais de saúde e pacientes}

A comunicação foi reconhecida como elemento fundamental e uma habilidade a ser desenvolvida na prestação do cuidado de saúde, destacando-se a sua complexidade e caráter dinâmico. Diversos fatores podem interferir na qualidade da comunicação entre profissionais de saúde e entre profissionais e pacientes, abrangendo desde características individuais dos sujeitos a circunstâncias do contexto. No contexto, importam, entre outros aspectos, as conjunturas organizacionais - fluxo do processo de trabalho, sobrecarga dos profissionais; a infraestrutura adequada ou não para preservação da privacidade; o nível de hierarquização das relações profissionais e a assimetria do conhecimento.

Os panelistas afirmaram que a assimetria de informação manifestada nas relações entre profissionais de saúde e pacientes, pode ser atenuada por técnicas de comunicação capazes de promover o melhor entendimento do paciente sobre a sua condição de saúde.

A Internet foi problematizada, sendo considerada uma ferramenta útil, capaz de esclarecer dúvidas, mas também perigosa ao apresentar informações, às vezes, pouco compreensíveis, com implicações na segurança do paciente.

\section{O compartilhamento de decisões e o cuidado centrado no paciente/pessoa}

A comunicação efetiva e o compartilhamento de decisões são indissociáveis para a prática do cuidado centrado no paciente. Incentivar a participação dos pacientes e familiares nas ações de cuidado, coopera para a co-responsabilização em relação ao próprio cuidado e à segurança do paciente, dependendo do grau de assimetria de conhecimento entre o profissional de saúde e o paciente.

A comunicação efetiva entre profissionais e pacientes e a utilização de estratégias que apoiemos pacientes nas decisões referentes à sua saúde favoreceriam a construção e o fortalecimento de vínculos e de confiança. 
Entretanto, a confiança durante a prestação dos cuidados de saúde é ameaçada por informes divulgados pelos meios de comunicação que evidenciam fatos negativos e sensacionalistas decorrentes da assistência à saúde, disseminando no meio social sentimentos de incerteza e desconfiança e contribuindo para o surgimento da "cultura do medo".

\section{Aspectos contextuais que interferem na continuidade do cuidado e adesão ao tratamento}

Tendo em vista a definição dos termos "continuidade do cuidado" e "adesão ao tratamento", o painel sugeriu um debate desagregado e particularizado, reforçando a ideia de complementariedade entre ambos, porém não excluindo características particulares no debate de cada termo. Segundo os especialistas, a "continuidade do cuidado" depende da maneira como as ações e serviços de saúde estão fisicamente organizadas dentro do sistema. Já a “adesão ao cuidado” reflete aspectos objetivos, assim como subjetivos, concernentes ao sujeito.

\section{A relação entre princípio da integralidade e o cuidado centrado no paciente/pessoa}

Segundo os especialistas, não cabia nos propósitos do painel a discussão isolada sobre integralidade, sem remetê-la previamente a um conceito que oriente o debate. A integralidade não pode ser garantida exclusivamente pela prática do cuidado centrado no paciente; a implementação dos elementos que conformam tal prática colabora para um cuidado integral.

\section{A incorporação do cuidado centrado no paciente/pessoa na formação técnica e universitária}

Foi reconhecida a necessidade de incluir disciplinas e abordagens pedagógicas que discutam, orientem e reflitam sobre condutas e comportamentos entre os sujeitos, apresentando estratégias capazes de aprimorar relações interpessoais e transformar práticas de cuidado.

A influência do setor privado na formação universitária de profissionais de saúde no Brasil, contribuindo para o predomínio da lógica de mercado em detrimento das práticas sociais e repercutindo no modo de produção dos cuidados de saúde, ocupou essa discussão. É socialmente importante repensar a formação do profissional de saúde, de modo a torná-la facilitadora da inserção do profissional nos sistemas de saúde, de forma mais interativa e menos fragmentada socialmente.

\section{O cuidado centrado no paciente para produção do cuidado seguro}

A legitimação da participação do paciente e seus familiares/acompanhantes no planejamento e execução dos cuidados em saúde foi vocalizada como uma estratégia para prevenção de incidentes. De acordo com os especialistas, o cuidado centrado no paciente e a segurança são dimensões da qualidade indissociáveis e complementares. Para tanto, fazem-se necessárias estratégias que promovam comunicação efetiva dos profissionais de saúde entre si e pacientes/ acompanhantes; o envolvimento dos pacientes e acompanhantes nos processos de cuidado e a disponibilização de evidências científicas para apoiar o compartilhamento das decisões.

\section{Formulação ou adaptação de instrumentos de mensuração do cuidado centrado no paciente/pessoa}

Segundo os especialistas, a utilização de instrumentos de mensuração de cuidado centrado no paciente adequada ao contexto de saúde brasileiro e capaz de indicar a real implementação desta prática na produção dos cuidado de saúde. Ela subsidiaria uma reorganização das práticas de saúde, de modo a torná-las mais centradas no paciente. Reconhecendo a importância dessa prática de atenção para melhorar a qualidade dos serviços de saúde, considerou-se possível adaptar ao contexto brasileiro ferramentas de mensuração já utilizadas em países desenvolvidos ou desenvolver instrumentos condizente com a cultura do cuidado no país.

\section{Trabalhos empíricos no Brasil sobre o cuidado centrado no paciente/pessoa}

O número de trabalhos empíricos no Brasil voltados para a área da qualidade do cuidado de saúde, de modo geral, ainda é insuficiente. Destacou-se a premência de fomentar o desenvolvimento de estudos nesta área visando, possíveis reordenações das práticas de saúde, de modo a torná-las mais centradas no paciente. 


\section{Discussão}

Resultados do painel mostraram-se alinhados à literatura no que concerne às diversas terminologias empregadas para referenciar a centralidade do cuidado de saúde, admitindo-se que apesar da intercambialidade entre elas, há nuances e atributos particulares. As conotações peculiares dependem de como as práticas de cuidado são implementadas e do contexto em que ocorre a produção do cuidado ${ }^{4}$, considerando que os aspectos contextuais determinam variações das práticas de saúde, sendo fundamental considerar o seu papel em intervenções para melhoria da qualidade do cuidado e segurança do paciente? ${ }^{9}$.

O contexto da realidade brasileira é complexo e contempla desde as condições e recursos disponíveis à disponibilidade de estudos empíricos sobre o cuidado centrado no paciente. Mesmo no contexto de um país como a Suécia, foram identificados desafios para a prática do cuidado centrado no paciente: baixo incentivo à participação dos pacientes; a priorização de aspectos objetivos em detrimento do subjetivo; conflitos de poder nas relações profissionais; infraestrutura inadequada dos serviços de saúde; profissionais que acreditam já realizar práticas centradas no paciente; diversidade cultural; e ausência de registros do cuidado de saúde ${ }^{10}$.

Considerando o cuidado centrado no paciente e a segurança do paciente como dimensões da qualidade indissociáveis, é central a identificação de estratégias para o envolvimento do paciente e acompanhantes na redução de danos evitáveis produzidos pelos serviços de saúde $\mathrm{d}^{8-11}$.

O compartilhamento de decisões entre profissionais de saúde, pacientes e acompanhantes foi declarado pelos participantes do painel como uma habilidade necessária na implementação da prática do cuidado centrado no paciente. Estudos mostram que, quando o paciente é envolvido nas decisões referentes ao seu tratamento, os desfechos clínicos são mais efetivos ${ }^{11,12}$. Porém, compartilhar decisões na prática de saúde exige dos profissionais envolvidos responsabilidades éticas, dada a assimetria do conhecimento técnico existente na relação com o paciente. É importante os profissionais de saúde apresentarem claramente as evidências e incertezas científicas existentes acerca de alternativas de tratamento ${ }^{12}$.

A ideia de que a comunicação é um elemento estratégico para o cuidado de saúde de qualidade perpassou vários pontos de discussão do painel, ficando assinalado que a sua efetividade favorece o compartilhamento de decisões, a coprodução dos serviços de saúde, aumenta a segurança do paciente, influenciando positivamente os resultados clínicos ${ }^{12-13}$. Comunicação eficaz é aquela que melhora a qualidade da assistência em saú$\mathrm{de}^{14}$. Mas, embora a comunicação seja reconhecida como uma ferramenta essencial, ela ainda enfrenta desafios nas esferas física e relacional. Segundo os participantes do painel, é vital criar condições favoráveis e projetos de melhoria que possam tornar a comunicação eficaz e, assim, promover um atendimento centrado no paciente.

A qualidade da formação profissional foi levantada como uma questão que precisa ser problematizada, repensada, e talvez, reformulada. Algumas instituições de ensino vêm implementando modificações curriculares em seus cursos de formação, incorporando disciplinas que oportunizam reflexões sobre as práticas de saúde ${ }^{15}$. Mas, em termos mais gerais, ainda prevalece a fragmentação do conhecimento, crescente especialização e valorizações tecnológica, com predomínio da visão biológica em detrimento da social $^{15}$.

Seria oportuno estabelecer conjunturas favoráveis à promoção de mudanças individuais e organizacionais facilitadoras da incorporação do cuidado centrado no paciente como um dos objetivos da qualidade do cuidado nos serviços de saúde brasileiros.

Em suma, a experiência aqui reportada possibilitou a agregação de diversos olhares e perspectivas sobre o cuidado centrado na pessoa/ paciente e elementos teóricos que o conformam. Contribuiu para a proposição de bases investigativas que permitirão um aprofundamento sobre o cuidado centrado na pessoa/paciente, com potencial agregação de evidências científicas sobre caminhos para a sua implementação e avaliação da sua efetividade no contexto de saúde brasileiro. 


\section{Colaboradores}

JLSQ Rodrigues trabalhou na pesquisa bibliográfica sobre o tema, redação, organização do evento, consolidação e análise dos resultados da discussão. MC Portela foi preponderante na orientação com relação à metodologia, organização do evento, revisora da redação final e indicação dos especialistas que compuseram o painel. AM Malik participou como membro do painel de especialistas que elaboramos na Escola Nacional de Saúde Pública/ENSP para discussão do tema cuidado centrado no paciente; atuou também como revisora final do material submetido, agregando considerações pertinentes sobre o tema discutido.

\section{Referências}

1. Donabedian A. The quality of care. How can it be assessed? JAMA 1988;260(12):1743-1748.

2. Sands KEF. Patient-centred care: confessions of a pragmatism. BMJ Qual Saf 2016;25(12):909-910.

3. Institute of Medicine. Crossing the quality chasm: a new health system for the 21st century. Washington, DC: National Academies Press (US); 2001.

4. Lines LM, Lepore M, Wienner JM. Patient-centered, person-centered, and person directed care: They are not the same. Med Care 2015;53(7):561-563.

5. The Health Foundation. Person-centred care made simple: what everyone should know about person-centred care. London: The Health Foundation; 2014.

6. Zhao J, Gao S, Wang J, Liu X, Hao Y. Differentiation between two healthcare concepts: person-centered care end patient-centered care. Intern J Nurs Sci 2016;3:398-402.

7. Ahmad N, Ellins J, Krelle H, Lawrie M. Person-centred care: from ideas to action: Bringing together the evidence on shared decision making and self-management support. London: The Health Foundation; 2014.

8. Picker Institute. Principles of patient-centered care. 2017.

9. Taylor SL, Dy S, Foy R, Hempel S, McDonald KM, Ovretveit J, Pronovost PJ, Rubenstein LV, Wachter RM, Shekelle PG. What context features might be important determinants of the effectiveness of patient safety practice interventions. BMJ Qual Saf 2011;20(7):611-617.

10. Moore L, Britten N, Lydahl D, Naldermici O, Elan M, Wolf A. Barriers and facilitators to the implementation of person-centred care in different healthcare context. Scand J Caring Sci 2017;31(4):662-673.

11. O'Hara JK, Lawton RJ. At a crossroads? Key challenges and future opportunities for patient involvement in patient safety. BMJ Qual Saf 2016;25(8):565-568.

12. Batalden M, Batalden P, Margolis P, Seid M, Armstrong G, Arrigan LO, Hartung R. Coproduction of healthcare services. BMJ Qual Saf 2016;25(7):509-517.

13. Norouzinia R, Aghabarari M, Shiri M, Karimi M, Samami E. Communication barriers perceived by nurses and patients. Glob J Health Sci 2015;8(6):65-74.

14. Paro HBMS. Empatia em estudantes de medicina no Brasil: um estudo multicêntrico [tese]. São Paulo: Faculdade de Medicina da Universidade de São Paulo; 2013.

15. Cooper A, Gray J, Wilson A, Lines C, McCannon J, McHardy KJ. Exploring the role of communications in quality improvement: A case study of the 1000 Lives Campaing in NHS Wales. Commun Health 2018;8(1):76-84. 
